$\xi=-1$

\title{
Characteristic of Silica Level (SiO3) Resulted from the Extraction of Rice Husk Ash with KOH Solvent towards the Amount of Heating Time
}

\author{
Riza Wirawan $^{1}$, Himawan Hadi Sutrisno ${ }^{1 *}$, Desi Ambarwati ${ }^{1}$, Andralisa Febriani ${ }^{1}$ \\ ${ }^{1}$ Faculty of Engineering. Universitas Negeri Jakarta, Jakarta \\ *Corresponding author E-mail: Himawan-hadi@unj.ac.id
}

\begin{abstract}
Silica is widely available in nature including the ones in the form of crystal granule, gel and colloid. Silica is known to have a higher boiling point than other materials. The production of silica gel from rice husk ash has a characteristic in the amount of silicone level which depends on its heating time during extraction. This research aims at increasing production of silicone element in rice husk ash extraction method using kalium hydroxide $(\mathrm{KOH})$, with heating time variation during its solution, namely between $15,30,45$ and 60 minutes. With an observation using EDS, the relationship of heating time toward the silicone level on the resulted material can be discovered. The 15-minute heating time contains the highest silicone level compared to the 30,45 or even 60 -minute heating time.
\end{abstract}

Keywords: Silica, Rice Husk Ash, $\mathrm{KOH}$.

\section{Introduction}

In an industrial scale, rice residue has not widely utilized as one of alternative materials that has high market value $[1,2]$. For example, the utilization of rice residue is only for livestock feed, fertilizer and mushroom planting media in a household industrial scale. In some countries, the production of rice is very abundant; Indonesia is no exception. Chemically, the residue of rice husk can be used as an alternative material for silica production, even though the final form of resulting silica is gel with certain characteristics [3-7].

Silica can be used as galvanized coating as it contains high thermal stability [8]. By homogenizing the nano composite of the silica, this procedure really supports the coated material towards the heat resilience [9]. When silica gel is used for coating materials like already performed using a fan, the materials will eventually have a high flash point $[10,11]$, thus by adding silica gel on certain material can increase the material property.

By using the extraction method, silica can be produced by rice husk ash [12]. In the study of Ya-Yu Hsieh [13], the rice husk ash can produce $\mathrm{Si}, \mathrm{Cl}, \mathrm{Na}$ and $\mathrm{K}$ elements, where the elements resulting from extraction can be utilized as needed. At the specification of Si element from rice husk ash, the extraction method using $\mathrm{KOH}$ solvent has been conducted by Carmona et al.[14]. In their research, silica is processed using acid solution and dissolved at heating temperature of $150^{\circ}$ Celsius and for a period of 60 minutes. By varying the solution of rice husk ash using $\mathrm{H}_{2} \mathrm{O}$, acetic acid, citric acid and $\mathrm{H}_{3} \mathrm{PO}_{4}$ the silica element in the atomic percentage ranges from 32.53 to 33.93 .

This occurs to the production of silica from rice husk ash using extraction with potassium hydroxide $(\mathrm{KOH})$ solvent, which in general the heating time required for the extraction is 60 minutes. Thus, in this research, experiments are conducted by distinguishing the heating time of $15,30,45$ and 60 minutes. To find out the influence of heating time on silica resulting from rice hush ash, the calculation of the amount of silica element in \% is conducted using Scanning electron microscope (SEM) and Energy dispersive microscopy (EDS) explained in the following sub-chapter.

\section{Research Method}

In order to produce silica from rice husk ash, firstly the rice husk that is free from dirt is selected. The chosen rice husk is then burned to ashes in which it will be used as a raw material of the silica production as research procedure described in the Figure 1.

To get ash from rice husk burning residue, the selected rice husk is the rice husk that has various dry level. It can be obtained by basking the rice husk under the sunlight for 14 days. After the raw material is obtained in the form of rice husk with various dry levels, then it is processed by burning it using furnace at a temperature of $600^{\circ}$ until the material turns to white ash.

From the burning outcomes, the rice husk ash is separated using a sieve shaker, thus the material with high homogeneity can be obtained. After an amount of rice husk ash is obtained, the rice husk ash is weighed with a certain measurement to be dissolved and heated to produce the silica gel. The solvent used can be either $\mathrm{NaOH}$ or $\mathrm{KOH}$. In this research, the solvent used is $\mathrm{KOH}$ with heating process at $85^{\circ} \mathrm{C}$.

The heating time can be selected from 15 to 60 minutes with 4 time variations. In each sample, the silica level will be measured by using SEM (Scanning Electron Microscope) and EDS (Energy Dispersive Spectroscopy) method to get the amount of element in $\%$ weight of sample and presented in the form of chart.

The SEM and EDS tools used are JEOL machine of 6510 (LA) type with the voltage of $20.000 \mathrm{kV}$. 


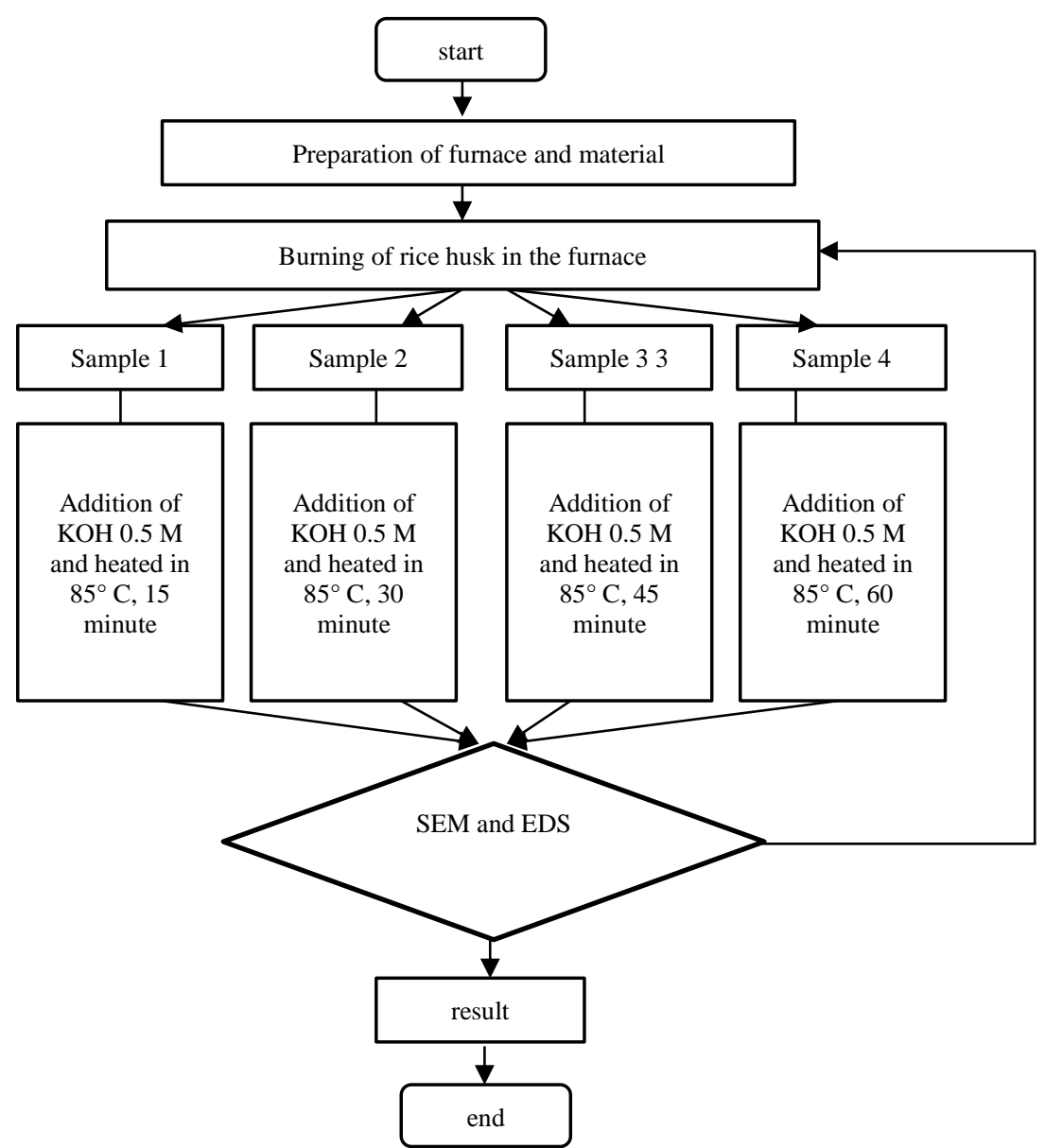

Fig. 1: flow chart of the research

\section{Result and Discussion}

From the rice husk ash, the selected ash contains a high homogeneity level. The ash to be used is filtered by using a sieve shaker, thus granules of the rice husk ash will be varied. The selected rice husk is the dried one and has brown color. On the other hand, the selected rice husk ash is the white one. The description can be seen in the following Figure 2 below.

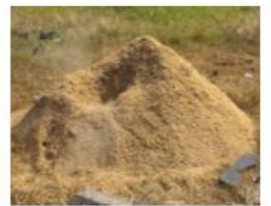

(a)

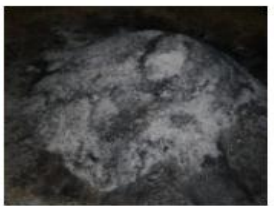

(b)

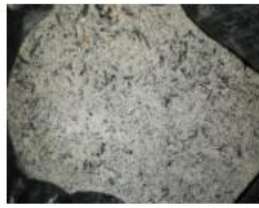

(c)
Fig. 2: (a) Rice husk as a raw material, (b) burning process of rice husk, (c) rice husk ash.

The result of each rice husk ash and solvent already heated in 4 time variations is filtered by using Whatman paper. This paper will separate filtrate and residue from the extraction of the rice husk ash. Every difference in heating time makes the silica gel contain elements in the form of silicone ( $\mathrm{Si})$, carbon (c), chlorine $(\mathrm{Cl})$, potassium $(\mathrm{K})$ and oxygen $(\mathrm{o})$. It can be proven from the result of SEM photo from each heating time. For the 60-minute heating time, the photos of SEM and EDS result can be seen in the following Figure 3.

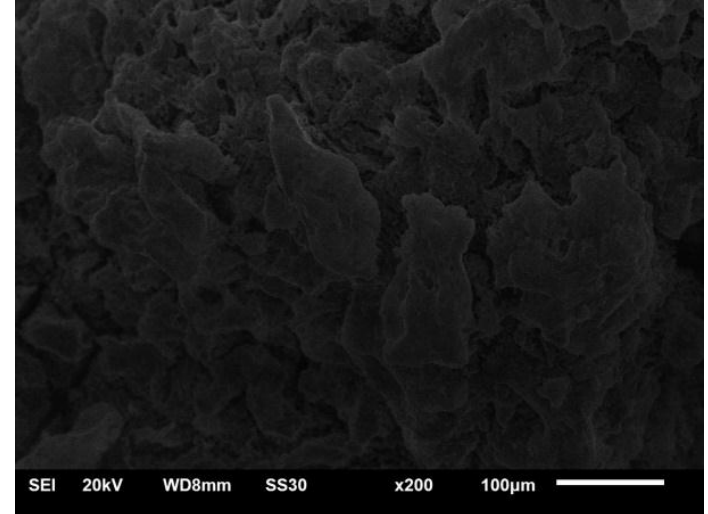

Fig. 3: SEM photo result of the silica gel with 60 minutes of heating time, zoomed to $200 \mu \mathrm{m}$

Then, the EDS result from the silica gel for the 60-minute heating time can be seen in the following Figure 4

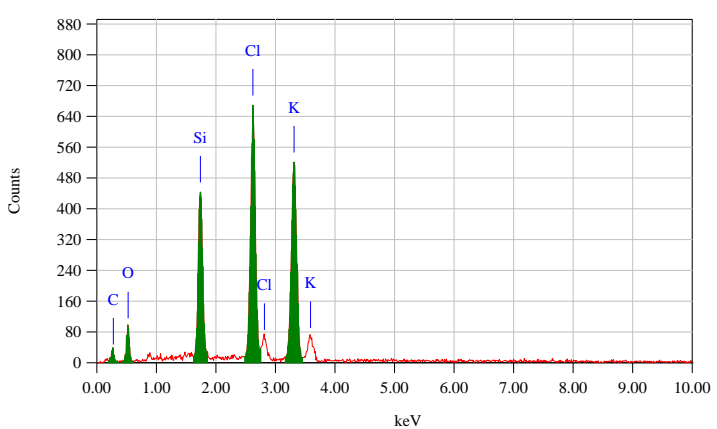

Fig. 4: EDS result of the silica gel with 60 minute heating time 
And the content of EDS result (as shown in table 1) of rice husk ash extraction using $\mathrm{KOH}$ solvent with 60 -minute heating time

Table 1. EDS result of rice husk ash extraction using $\mathrm{KOH}$ solvent with 60-minute heating time

\begin{tabular}{|c|c|c|c|c|c|c|c|}
\hline \multicolumn{8}{|c|}{$\begin{array}{l}\text { ZAF Method Non-Standard Quantitative Analysis } \\
\text { Fitting Coefficient }: \mathbf{0 . 3 2 7 4}\end{array}$} \\
\hline Element & $(\mathrm{keV})$ & Mass\% & Error\% & Atom\% & Compound & Cation & $\mathrm{K}$ \\
\hline C K & 0.277 & 24.04 & 1.42 & 38.66 & & & 4.1282 \\
\hline O K & 0.525 & 29.42 & 0.99 & 35.52 & & & 19.5503 \\
\hline Si K & 1.739 & 9.81 & 0.13 & 6.75 & & & 14.3460 \\
\hline Cl K & 2.621 & 17.99 & 0.13 & 9.80 & & & 31.8516 \\
\hline K K & 3.312 & 18.75 & 0.18 & 9.26 & & & 30.1239 \\
\hline total & & 100.0 & & 100.00 & & & \\
\hline
\end{tabular}

From the preceding data, it can be seen that there are several elements contained in the silica gel material. The data above shows the silicone level ( $\mathrm{Si}$ ) at $9.81 \%$ of mass, carbon level (C) $24.04 \%$, chlorine level $(\mathrm{Cl}) 17.99 \%$, potassium level $(\mathrm{K}) 18.75 \%$ and oxygen level (O) $29.42 \%$. At each difference in heating time, from 15 ,
30,45 and 60 minutes, the characteristic of silica produced has a significant difference. It can be seen in the SEM photo result as in Table 2. Meanwhile, for the element content in \% of mass from each tested sample, the difference in silica can be seen from the difference in heating time as seen in Table 3.

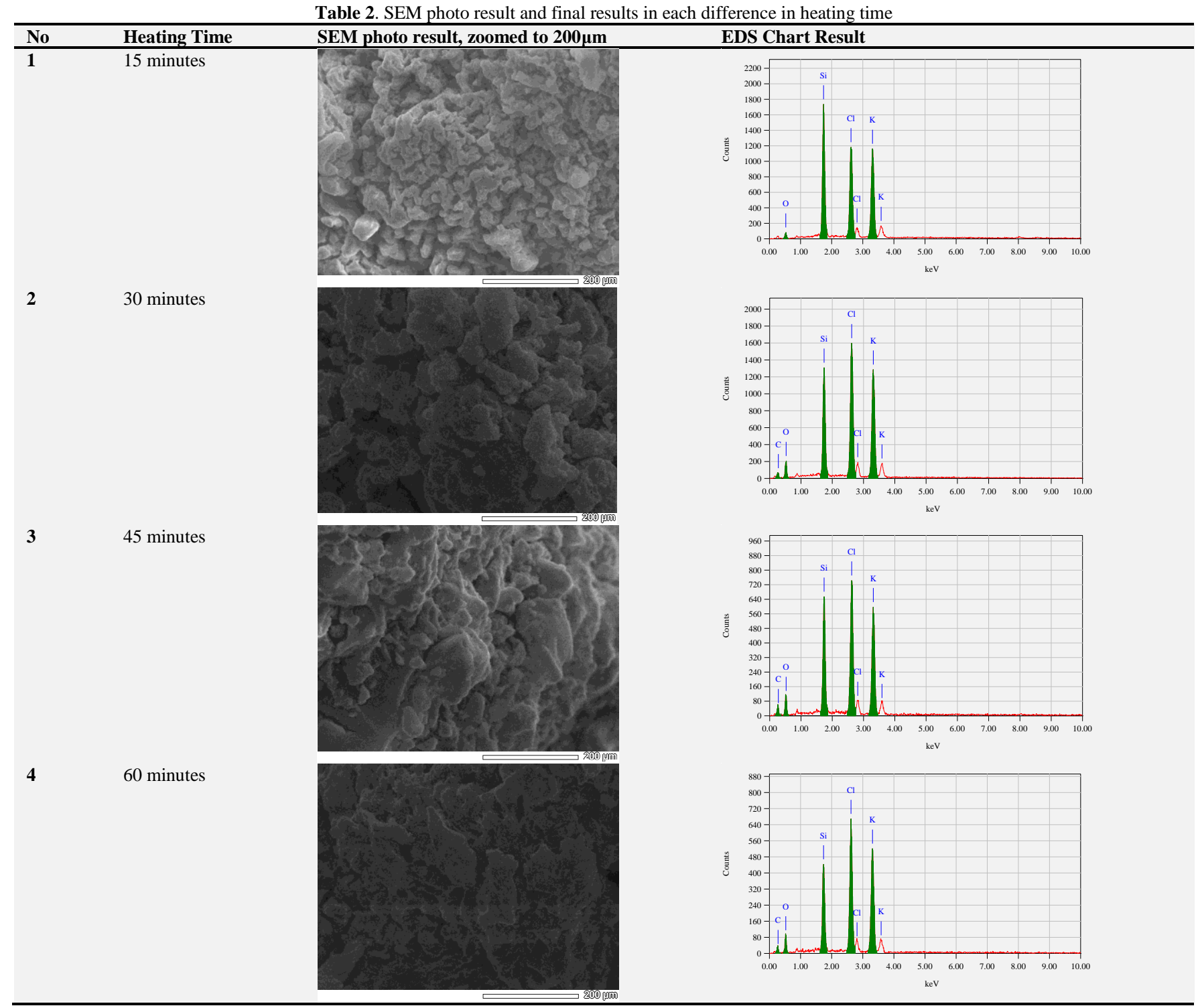

Table 3. Comparison of EDS result with various heating time

\begin{tabular}{|c|c|c|c|c|c|c|c|}
\hline No. & Heating Time & $\begin{array}{l}\text { Acquisition Parameter } \\
\text { Instrument }\end{array}$ & $\mathbf{S i}$ & $\mathbf{C}$ & $\mathrm{Cl}$ & $\mathbf{K}$ & $\mathbf{O}$ \\
\hline 1 & 15 minutes & $6510(\mathrm{LA})$ & 24.73 & 18.69 & 22.82 & 28.54 & 17.91 \\
\hline 2 & 30 minutes & Acc. Voltage : $20.0 \mathrm{kV}$ & 11.58 & 20.58 & 19.39 & 20.41 & 28.05 \\
\hline 3 & 45 minutes & Probe Current: $1.00000 \mathrm{nA}$ & 10.39 & 29.50 & 15.86 & 16.11 & 28.14 \\
\hline 4 & 60 minutes & $\begin{array}{ll}\text { PHA mode } & : \text { T3 } \\
\text { Real Time } & : 18.48 \mathrm{sec}\end{array}$ & 9.81 & 24.04 & 17.99 & 18.75 & 29.42 \\
\hline
\end{tabular}


Live Time $: 15.00 \mathrm{sec}$
Dead Time $: 18 \%$
Counting Rate: $3315 \mathrm{cps}$
Energy Range : $0-20 \mathrm{keV}$

From the table 3, it can be seen that the mass of the silica element contained in the silica sample heated for 15 minutes is $24.73 \%$. However, when the heating time is prolonged to 30 minutes, the mass of the silica element decreases to $11.58 \%$. From those two sample results, there is an indication of a decrease in the produced silica mass when the heating time of extraction is prolonged. To ensure such indication, it can be proven by seeing the test result of a sample heated for 45 minutes and evidently the result shows that there is indeed a decrease. The mass of the silica obtained from this sample is $10.39 \%$ (See Fig.5).

The process with longer extraction time can evidently produce a solvent with less filtrate result and such filtrate acidification can only produce a very little amount of silica. This result indicates that a longer extraction time causes most of the silica not to sediment perfectly, thus it causes a decrease in the silica level.

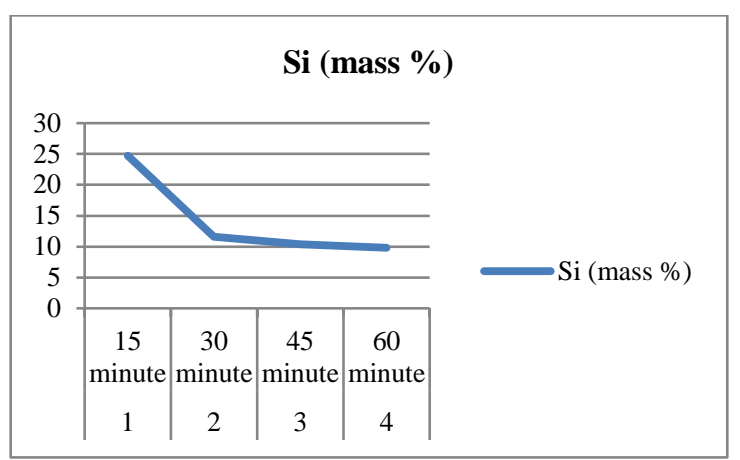

Fig. 5: Difference in silicon element in EDS result at every variant of heating time

Meanwhile, carbon (C) element with the heating time of 15 to 60 minutes produces an increase as describe in Figure 6. Likewise, the oxygen level contained in the extracted silica gel is described in Figure 7.

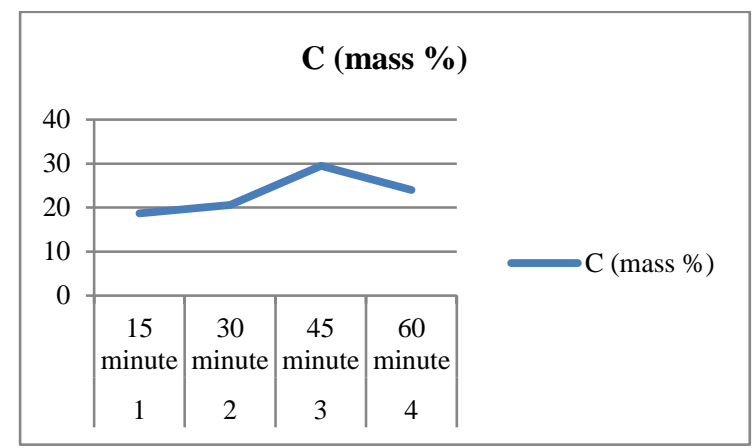

Fig. 6: Difference in Carbon element in the extracted silica gel

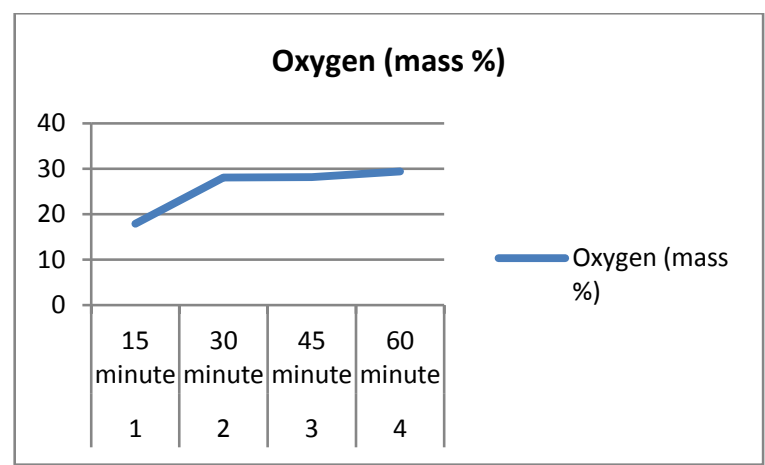

Fig. 7: Difference in Oxygen element in the extracted silica gel

\section{Conclusion}

From the extraction result using the variant of 15 to 60 minutes of heating time, rice husk ash produces silica gel with the highest silicone level at the 15 minute heating time, with the level at $24 \%$. It is clearly far different from the ones using the 60 minute heating time. On the other hand, other elements such as carbon and oxygen increase in its percentage according to the increase in heating intensity at extraction time. Chlorine and potassium elements show a different result, which experiences a decrease in level from $14 \%$ to $10 \%$.

\section{References}

[1] R. Pode, "Potential applications of rice husk ash waste from rice husk biomass power plant," Renewable and Sustainable Energy Reviews, vol. 53, pp. 1468-1485, 2016.

[2] N. Soltani, A. Bahrami, M. I. Pech-Canul, and L. A. González, "Review on the physicochemical treatments of rice husk for production of advanced materials," Chemical Engineering Journal, vol 264, pp. 899-935, 2015.

[3] Y. Liu, Y. Guo, W. Gao, Z. Wang, Y. Ma, and Z. Wang, "Simultaneous preparation of silica and activated carbon from rice husk ash," Journal of Cleaner Production, vol. 32, pp. 204-209, 2012.

[4] Y. Shen, P. Zhao, and Q. Shao, "Porous silica and carbon derived materials from rice husk pyrolysis char," Microporous and Mesoporous Materials, vol. 188, pp. 46-76, 2014.

[5] H. Mohamed and M. Lamia, "Implementing flipped classroom that used an intelligent tutoring system into learning process," Computers \& Education, vol. 124, pp. 62-76, 2018.

[6] M. Nabil, K. R. Mahmoud, A. El-Shaer, and H. A. Naiber, "Preparation of crystalline silica (quartz, cristobalite, and tridymite) and amorphous silica powder (one step)," Journal Of Physic and Chemistry of Solid, vol. 121, p. 5, 2018.

[7] S. H. Kwon, I. H. Park, C. M. Vu, and H. J. Choi, "Fabrication and electro-responsive electrorheological characteristics of rice huskbased nanosilica suspension," journal of Taiwan Institute of Chemical Engineering, 2018.

[8] Y. Shi and G. Wang, "The novel silicon-containing epoxy/PEPA phosphate flame retardant for transparent intumescent fire resistant coating," Applied Surface Science, vol. 385, pp. 453-463, 2016.

[9] S. Sembiring, W. Simanjuntak, R. Situmorang, A. Riyanto, and K. Sebayang, "Preparation of Refractory cordierite using amorphous rice husk silica for thermal insulation purpose," Ceramics International, vol. 42, p. 6, 2016

[10] Q. Wu, Q. Zhang, L. Zhao, S.-N. Li, L.-B. Wu, J.-X. Jiang, et al., "A novel and facile strategy for highly flame retardant polymer foam composite material: Tranforming silicone resin coating into silica self-extinguishing layer," Journal of Hazardous Material, vol. 336, p. 10, 2017.

[11] A. Beaugendre, S. Degeutin, S. Bellayer, C. pieriot, S. Duguesne, M. Casetta, et al., "Self-stratifying epoxy/silicone coating," Progress in Organic Coating, vol. 103, p. 10, 2017.

[12] S. K. S. Hossain, L. Mathur, P. Singh, and M. R. Majhi, "Preparation of forsterite refractory using highly abundant amorphous rice husk silica for thermal insulation," Journal of Asian Ceramic Societies, vol. 5, pp. 82-87, 2018.

[13] Y.-Y. Hsieh, Y.-C. Tsai, J.-R. He, P.-F. Yang, H.-P. Lin, C.-H. Hsu, et al., "Rice husk agricultural waste-derived low ionic content carbon-silica nanocomposite for green reinforced epoxy resin electronic packaging material," Journal of The Taiwan Institute of Chemical Engineers, vol. 78, p. 7, 2017.

[14] V. B. Carmona, R. M. Oliveira, W. T. L. Silva, and L. H. C., "Nanosilica from rice husk: Extraction and Characterization," Industrial Crops and Products, vol. 43, p. 6, 2013. 